\title{
Elucidation of MHD Boundary Layer Flow Past a Plate with Viscous Dissipation
}

\author{
Bhrigu Kumar Kalita ${ }^{1}$, Rita Choudhury ${ }^{2}$, Paban Dhar ${ }^{3}$ \\ 1, 2 Department of Mathematics, Gauhati University, Guwahati-781014, Assam, India. \\ ${ }^{3}$ Department of Mathematics, Karimganj College, Karimganj- 788710, Assam, India.
}

\begin{abstract}
An exploration is contrived to represent an electrically conducting boundary layer flow past a vertical permeable plate in existence of viscous dissipation and chemical reaction. The simultaneous heat and mass transfer characteristics are considered into account. The magnetic Reynolds number is considered to be very small. The problem has been solved numerically. To get physical insight of the problem, the pertinent flow characteristics are discussed graphically. The results obtained are relevant with the classical results. The applications of such model have been noticed in industrial and chemical processes.
\end{abstract}

Keywords: MHD, boundary layer, viscous dissipation, skin friction, Nusselt number.

\section{INTRODUCTION}

The subject of fluid flow accompanied by heat and mass transmission continues to cause much interest within the scientific community. This is mainly because of their applications in many industrial aspects such as the compact heat exchangers, chemical distillation, cooling of the electronic components, solar energy collectors, and others. Generally, such type of flows are characterized by the existence of the temperature and concentration gradients which in turn engender thermal and solutal buoyancy forces. The process of mass and heat transmission in presence of chemical reaction and porous surface has engrossed the attention of scientists in perspective of their industrial applicability. The contributions of the scientists viz. Khair and Bejan [1],[2], Doma et al. [3], Hossain et al. [4], Kumar [5], Sharma and Singh [6], Ganesan and Palani [7], Chen[8], Hossain et al. [9], Raptis et al. [10], Ahmed and Sarkar [11] and Chand et al. [12] are gratefully acknowledged in this study.

Due to simplicity, chemical reaction of order one has been contemplated here. Anjali Devi and Kandasamy [13],[15], Kumar [14] have augmented their studies in extant of chemical reaction. Chen [16] has examined the combined heat and mass transmission characteristics along with viscous dissipation for MHD free convective flow.

\section{MATHEMATICAL FORMULATION}

A steady boundary layer flow with heat and mass transfer past a semi-infinite vertical porous plate has been reckoned. A uniform magnetic field is adapted perpendicular to the plate. Let $\bar{u}$ and $\bar{v}$ be the components of the velocity along the coordinate axes $\bar{x}$ and $\bar{y}$ respectively where $\bar{x}$ and $\bar{y}$-axes are taken along and normal to the plate respectively. The induced magnetic field has been neglected.

The governing equations are :

$$
\begin{aligned}
& \frac{\partial \bar{v}}{\partial \bar{y}}=0, \quad \text { this implies } \bar{v}=-v_{0}, v_{0}>0 \\
& -v_{0} \frac{\partial \bar{u}}{\partial \bar{y}}=v \frac{\partial^{2} \bar{u}}{\partial \bar{y}^{2}}+g \beta\left(\bar{T}-\bar{T}_{\infty}\right)+g \beta^{*}\left(\bar{C}-\bar{C}_{\infty}\right) \\
& -\frac{v}{k_{0}} \bar{u}-\frac{\sigma B_{0}{ }^{2}}{\rho} \bar{u} \\
& -v_{0} \frac{\partial \bar{T}}{\partial \bar{y}}=\frac{\kappa}{\rho C_{p}} \frac{\partial^{2} \bar{T}}{\partial \bar{y}^{2}}+\frac{v}{C_{p}}\left(\frac{\partial \bar{u}}{\partial \bar{y}}\right)^{2}+\frac{\sigma B_{0}{ }^{2}}{\rho C_{p}} \bar{u} \\
& -v_{0} \frac{\partial \bar{C}}{\partial \bar{y}}=D \frac{\partial^{2} \bar{C}}{\partial \bar{y}^{2}}-k_{l}\left(\bar{C}-\bar{C}_{\infty}\right)
\end{aligned}
$$

The relevant boundary conditions are:

$\bar{y}=0 ; \quad \bar{u}=0, \bar{T}=\bar{T}_{0}, \bar{C}=\bar{C}_{0}$

$\bar{y} \rightarrow \infty ; \bar{u} \rightarrow 0, \quad \bar{T} \rightarrow \bar{T}_{\infty}, \bar{C} \rightarrow \bar{C}_{\infty}$

For convenience, the dimensionless parameters are initiated as follows:

$$
\begin{aligned}
& y=\frac{v_{0}}{v} \bar{y}, \quad u=\frac{\bar{u}}{v_{0}}, \theta=\frac{\bar{T}-\bar{T}_{\infty}}{\bar{T}_{0}-\bar{T}_{\infty}}, \quad \phi=\frac{\bar{C}-\bar{C}_{\infty}}{\bar{C}_{0}-\bar{C}_{\infty}}, \\
& M=\frac{\sigma v B_{0}^{2}}{\rho v_{0}^{2}}, K=\frac{k_{0} v_{0}^{2}}{v^{2}}, G r=\frac{g \beta v\left(\bar{T}_{0}-\bar{T}_{\infty}\right)}{v_{0}^{3}} \\
& \operatorname{Pr}=\frac{\mu C_{p}}{\kappa}, G m=\frac{g \beta^{*} v\left(\bar{C}_{0}-\bar{C}_{\infty}\right)}{v_{0}^{3}}, \gamma=\frac{v K_{l}}{v_{0}^{2}} \\
& E=\frac{v_{0}^{2}}{C_{p}\left(\bar{T}_{0}-\bar{T}_{\infty}\right)}, S c=\frac{v}{D}
\end{aligned}
$$

Non-dimensional forms of governing equations are:

$$
\frac{d^{2} u}{d y^{2}}+\frac{d u}{d y}-\left(M+\frac{1}{K}\right)=-G r \theta-G m \phi
$$




$$
\begin{aligned}
& \frac{d^{2} \theta}{d y^{2}}+\operatorname{Pr} \frac{d \theta}{d y}+\operatorname{Pr} E\left(\frac{d u}{d y}\right)^{2}+\operatorname{Pr} M E u^{2}=0 \\
& \frac{1}{S c} \frac{d^{2} \emptyset}{d y^{2}}+\frac{d \emptyset}{d y}-\gamma \phi=0
\end{aligned}
$$

The correlated boundary conditions are:

$$
\begin{aligned}
& y=0 ; \quad u=0, \quad \theta=1, \phi=1 \\
& y \rightarrow \infty ; \quad u \rightarrow 0, \quad \theta \rightarrow 0, \quad \phi \rightarrow 0
\end{aligned}
$$

\section{METHOD OF SOLUTION}

Numerical technique has been employed to solve the equations (7) to (9) under boundary conditions (10). MATLAB's built in solver bvp4c is used in this problem.

\section{RESULTS AND DISCUSSION}

The execution of mass and heat transmission on magnetohydrodynamic boundary layer flow past a permeable plate in subsistence of viscous dissipation as well as chemical reaction have been analyzed. The relevant flow characteristics are illustrated graphically in figures 1 to 22 . We examine the effect of each non-dimensional parameters involved in the study while keeping the others constant. Throughout the discussion, the values of parameters are taken as $\mathrm{M}=2$, $\mathrm{Gr}=5, \mathrm{Gm}=5, \mathrm{Sc}=5, \mathrm{E}=0.05, \mathrm{~K}=1, \gamma=0.5$ and $\mathrm{Pr}=0.72$ unless otherwise stated. The arbitrariness of the dimensionless fluid parameters or constants are in accordance with the underlying theory.

The figures 1 to 10 exhibit the effects of various flow parameters involved in this study on the fluid velocity. In this problem, the flow structure is discussed for both externally cooled plate $(G r>0)$ and heated plate $(G r<0)$ respectively. Figure 1 indicates that the enhancement of Prandtl number diminishes the fluid velocity in case of cooling problems. Figure 2 depicts the exactly opposite scenario for heating problems. It is noticed from the figures 3 and 4 that the rising value of positive $G r$ enhances the speed of the fluid velocity while diminishing values of negative $\mathrm{Gr}$ decreases the velocity. Figures 5 and 6 display the distribution of fluid velocity for various values of magnetic field parameter M. It is observed that growth in magnitude of $\mathrm{M}$ diminishes the absolute value of fluid velocity. This is due to the fact that the magnetic field in action generates a resistive force called Lorentz force which has a tendency to retard the velocity of the flow. Figures 7 and 8 reveal the effect of Schmidt number in this study. For both cooled plate and heated plate, the rise of Schmidt number $S c$ exhibits decelerating trend of the fluid velocity. Figures 9 and 10 demonstrate the effect of chemical reaction parameter $\gamma$ on the fluid velocity. It is noticed that in cooling problem, as the chemical reaction parameter goes up, the velocity decreases but there is not much of significant difference between two adjacent velocity graphs for most part along y-axis. In case of heated plate a similar argument can be put forwarded. This can be summed up by stating that chemical reaction of order one has comparatively meager effect on fluid velocity than other flow parameters.
The variations of temperature $\theta$ against distance $\mathrm{y}$ are displayed from figures 11 to 14 to explain the influence of Prandtl and Eckert numbers on flow temperature in presence of different flow parameters for both cooled and heated plates. Figures 11 and 12 illustrate that with the growth in Prandtl number the temperature of the flow field decreases for both cooled and heated plates. It is also noted that for very small Prandtl number, temperature decreases almost linearly as one moves away from the plate. However for comparatively larger Prandtl number temperature diminishes steeply near the plate and then falls asymptotically as one moves to infinity. Figures 13 and 14 exhibit the fact that rise in Eckert number causes rise in flow temperature in both cooled and heated plates, but the difference in temperature is not much significant. Figures 15 and 16 reveal that the concentration profile diminishes sharply close to the plate and then proceeds uniformly away from the plate. Figures 17 to 19 illustrate the influence of different flow parameters on skin friction. For cooled plate $(G r>0)$ the skin friction declines with the increasing value of Prandtl number and magnetic parameter but shows opposite trend for heated plate $(G r<0)$. Figures 20 to 22 exhibit the influence of flow parameters on Nusselt number. From these figures, it is observed that increase in Prandtl number as well as magnetic and chemical parameters enforce a declination in the heat flux of the flow.

\section{FIGURES}

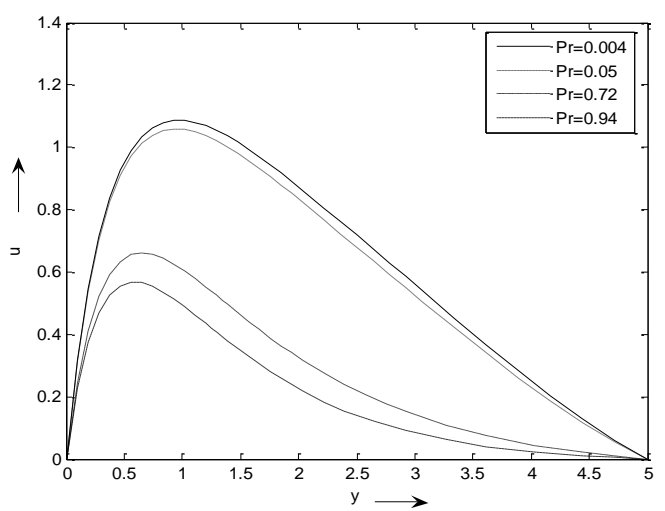

Figure 1: Impact of Pr on velocity for $\mathrm{Gr}>0$

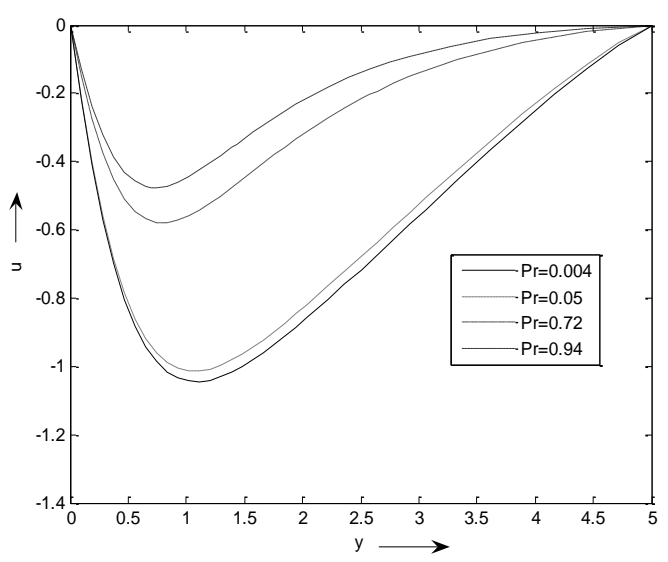

Figure 2: Impact of $\mathrm{Pr}$ on velocity for $\mathrm{Gr}<0$ 


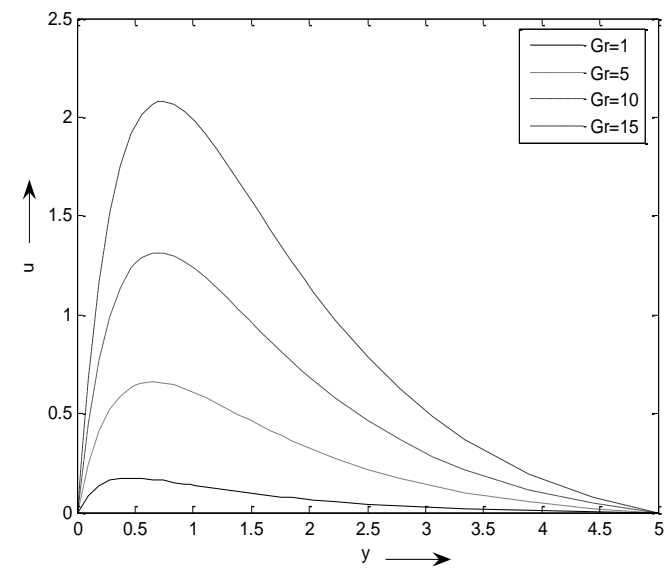

Figure 3: Impact of positive Gr on velocity

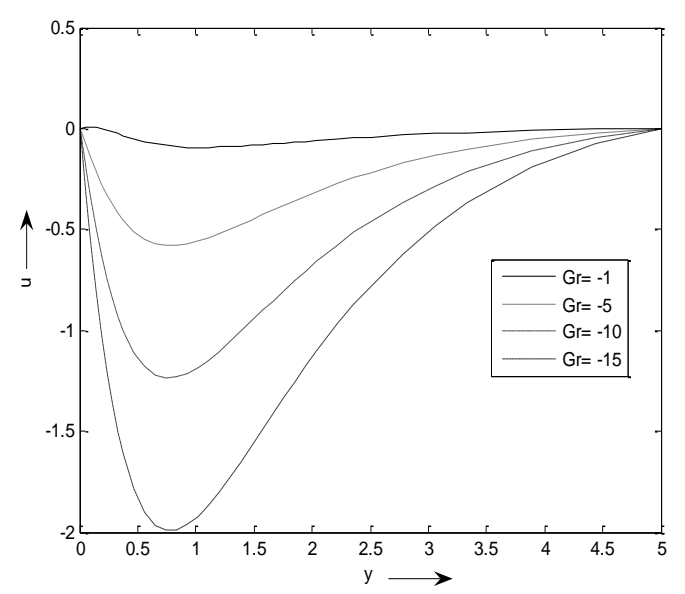

Figure 4: Impact of negetive Gr on velocity

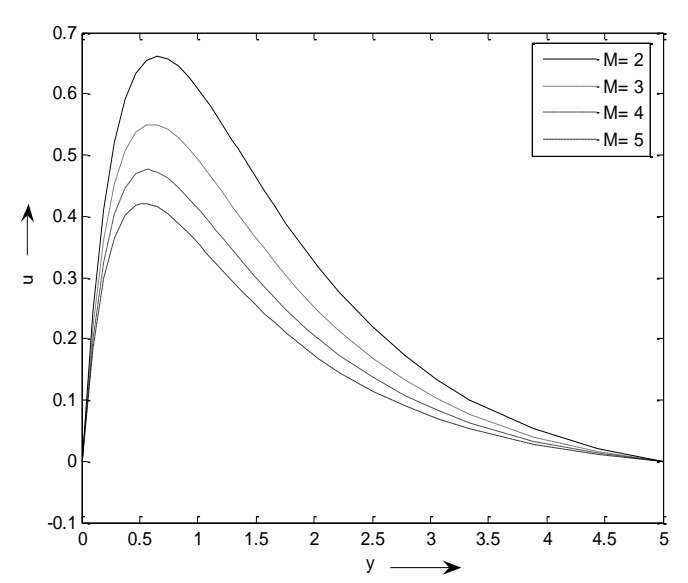

Figure 5: Impact of $\mathrm{M}$ on velocity for $\mathrm{Gr}>0$

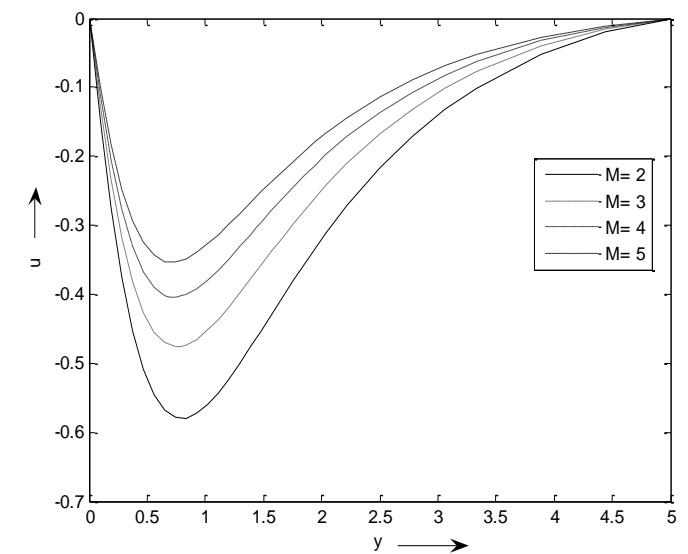

Figure 6: Impact of $M$ on velocity for $\mathrm{Gr}<0$

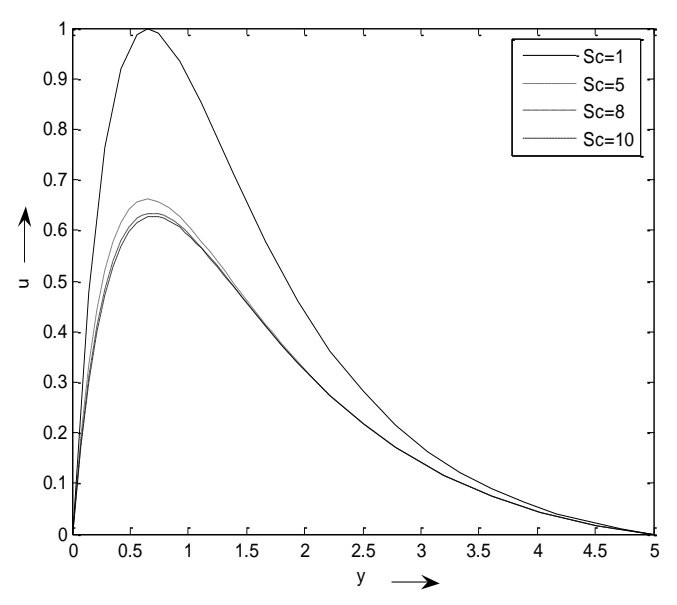

Figure 7: Impact of $\mathrm{Sc}$ on velocity for $\mathrm{Gr}>0$

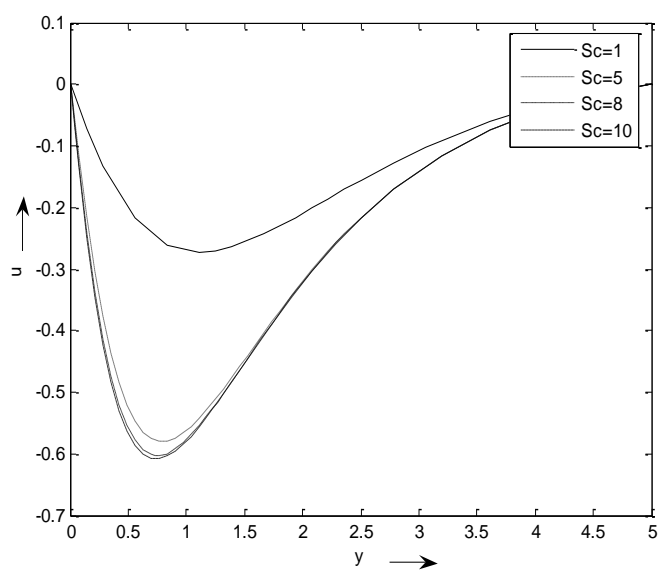

Figure 8: Impact of $\mathrm{Sc}$ on velocity for $\mathrm{Gr}<0$ 


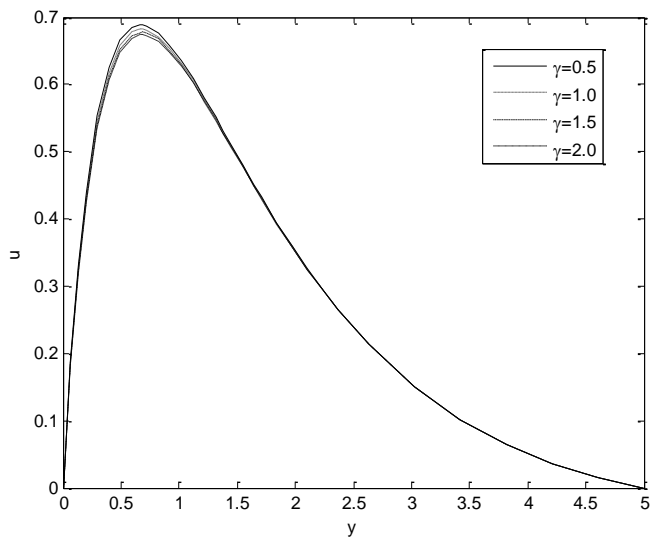

Figure 9: Impact of $\gamma$ on velocity for $\mathrm{Gr}>0$

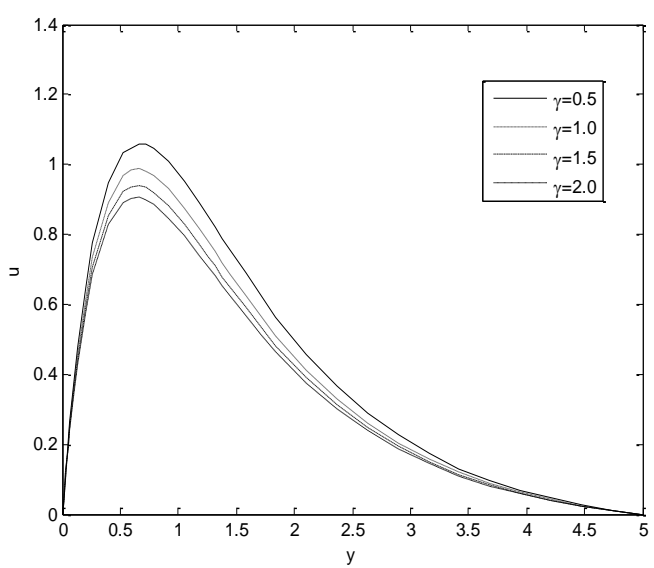

Figure 10: Impact of $\gamma$ on velocity for $\mathrm{Gr}<0$

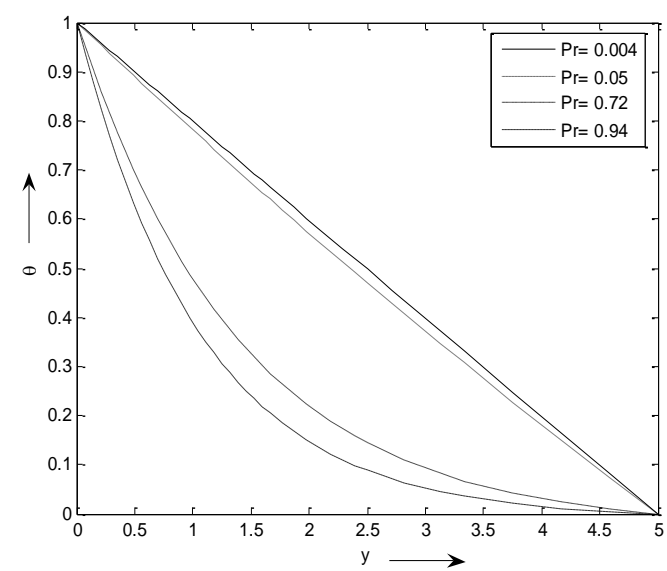

Figure 11: Impact of Pr on temperature for $\mathrm{Gr}>0$

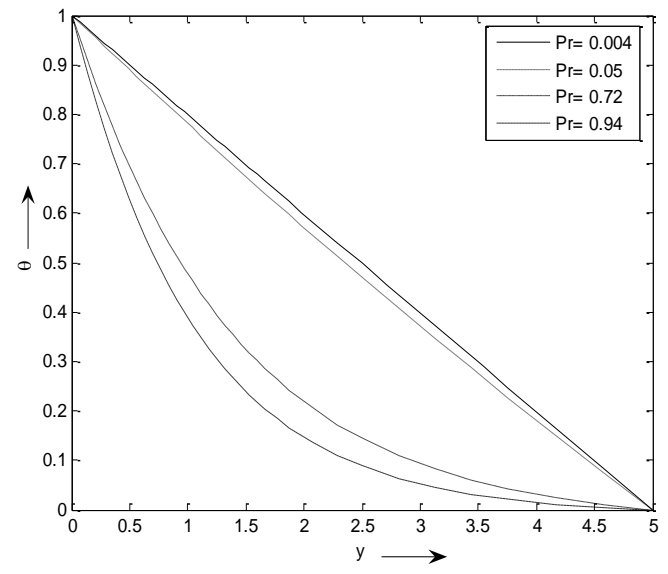

Figure 12: Impact of $\mathrm{Pr}$ on temperature for $\mathrm{Gr}<0$

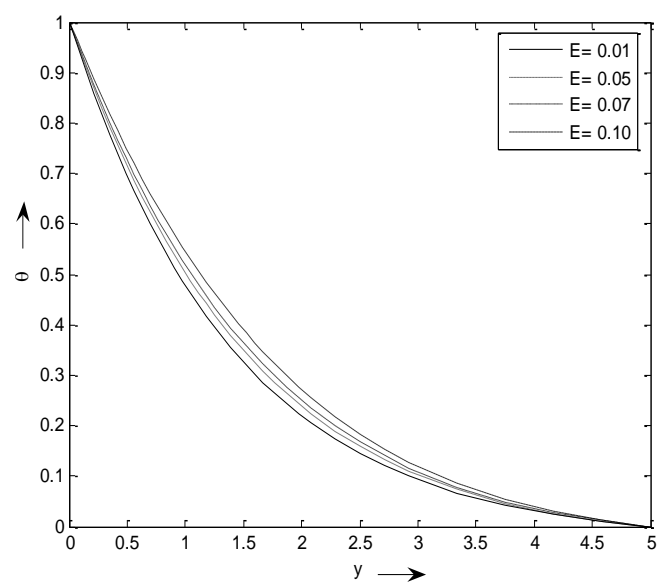

Figure 13: Impact of $\mathrm{E}$ on temperature for $\mathrm{Gr}>0$

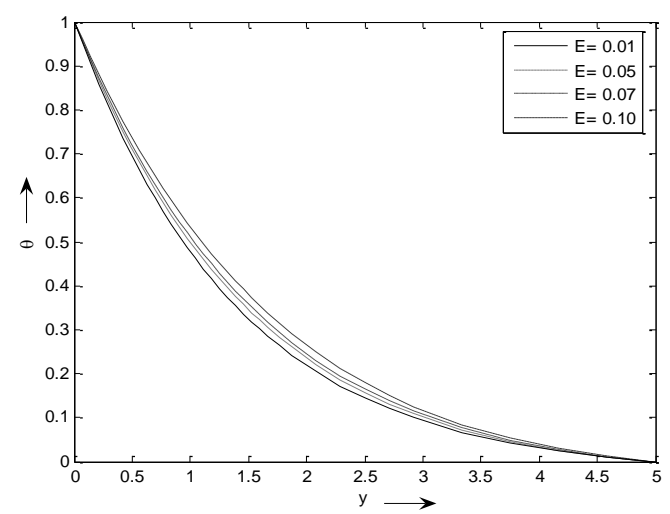

Figure 14: Impact of $\mathrm{E}$ on temperature for $\mathrm{Gr}<0$ 


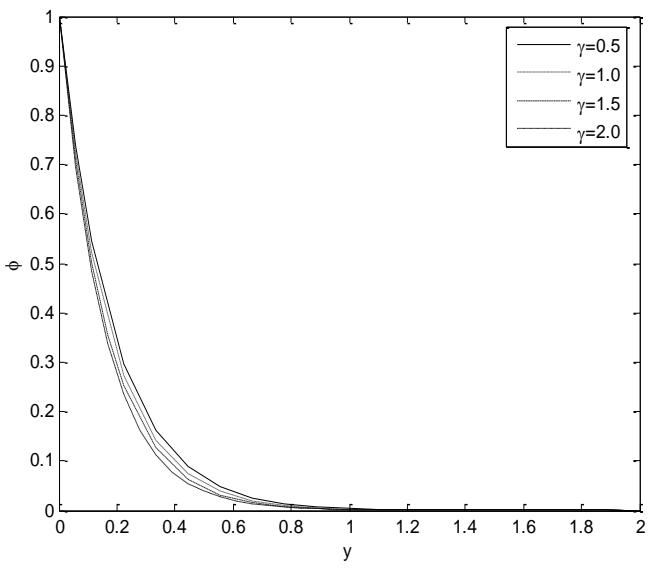

Figure 15: Impact of $\gamma$ on concentration

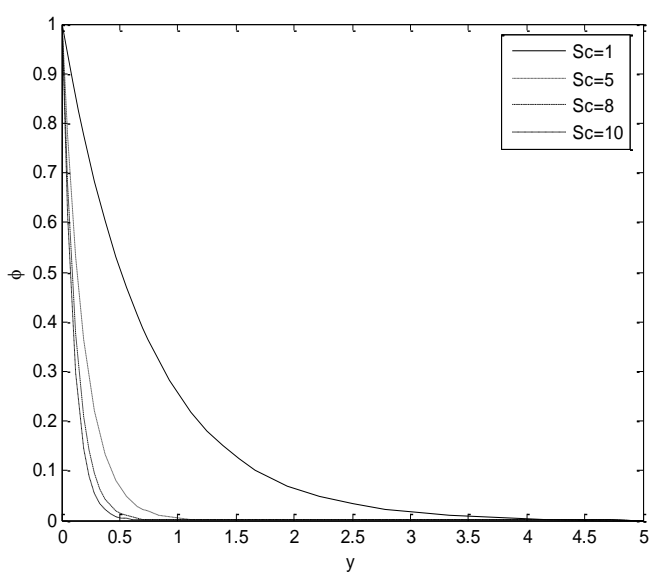

Figure 16: Impact of Sc on concentration

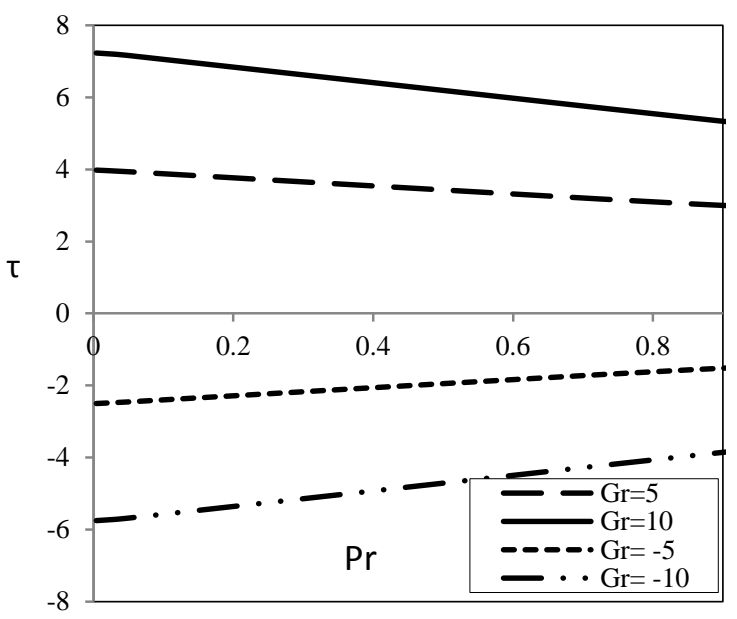

Figure 17: Impact of Pr on skin friction

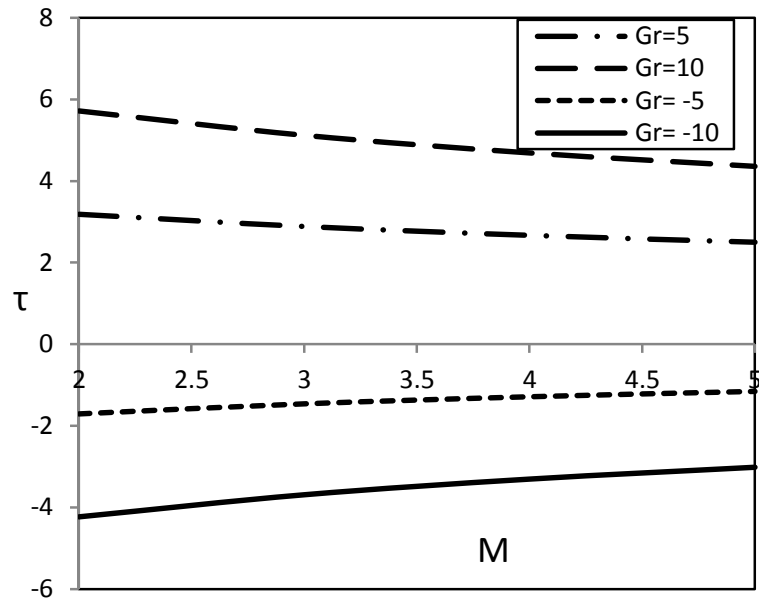

Figure 18: Impact of $M$ on skin friction

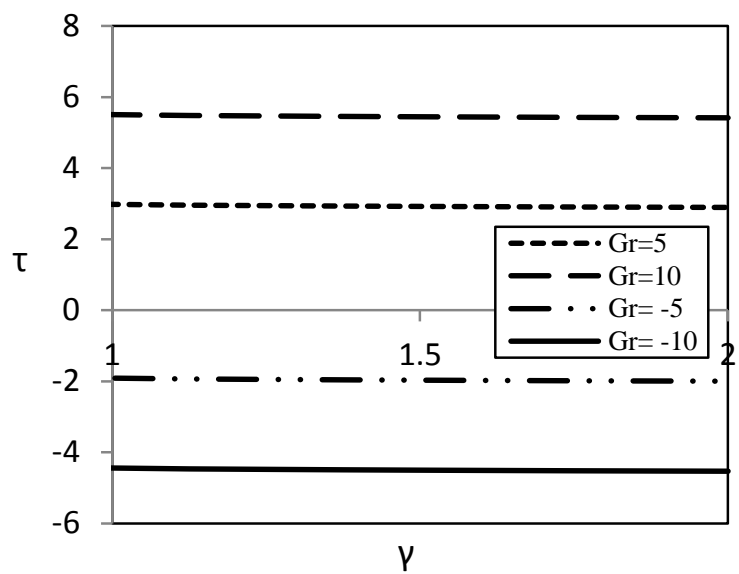

Figure 19: Impact of $M$ on skin friction

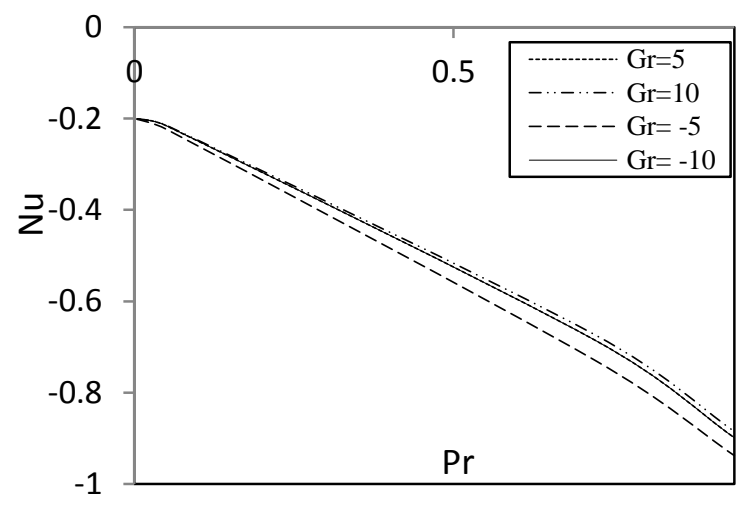

Figure 20: Impact of Pr on Nusselt number 


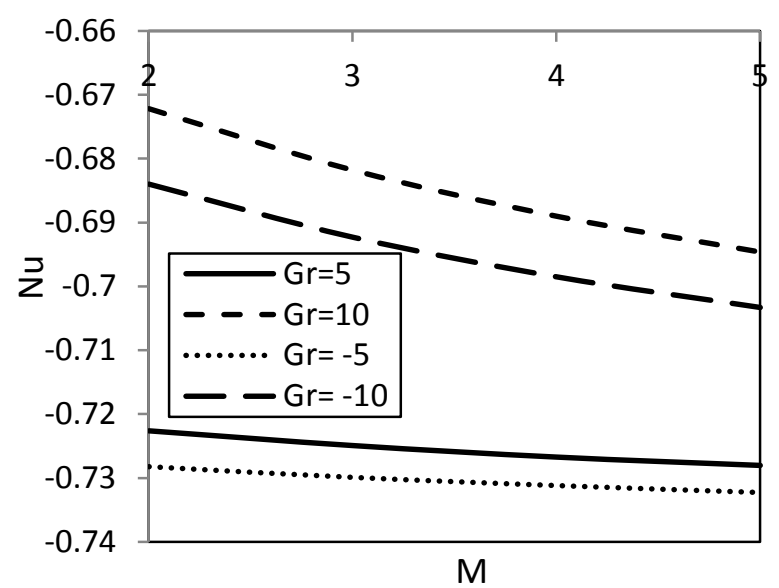

Figure 21: Impact of $M$ on Nusselt number

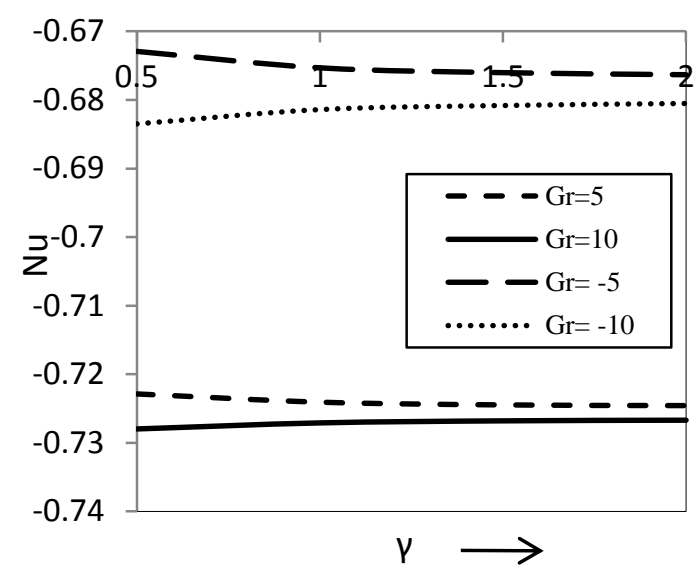

Figure 22: Impact of $\gamma$ on Nusselt number

\section{CONCLUSION}

The following are some principal results obtained from the study:

1) The fluid velocity shows sudden increment in case of cooled plate and decrement in case of heated plate respectively, near the plate but shows gradual asymptotic approach towards rest when moved far away from it in the fluid flow region for the variation of pertinent fluid flow parameters.

2) The rise of Prandtl number decelerates the fluid temperature but the opposite trend is observed by the action of Eckert number.

3) Sherwood number improves with the enhancement of Schmidt number and chemical reaction parameter.

4) The skin friction gets enhanced for cooled plate but the opposite phenomenon happens for heated plate in case of both Prandtl number and magnetic parameter.

5) Nusselt number reduces quite quickly with the variation of Prandtl number and magnetic parameter for both cooled and heated plates.

\section{ACKNOWLEDGEMENT}

This work is financially supported by University Grants Commission.

\section{SYMBOLS AND ABBREVIATIONS}

$\bar{u} \quad$ velocity component along $\bar{x}$ axis

$\bar{v} \quad$ velocity component along $\bar{y}$ axis

$g \quad$ acceleration due to gravity

$v_{0} \quad$ suction velocity at the plate

$\bar{T} \quad$ fluid temperature

$\bar{T}_{0} \quad$ temperature of plate

$\bar{T}_{\infty} \quad$ fluid temperature away from plate

$\bar{C} \quad$ fluid concentration

$\bar{C}_{0} \quad$ fluid concentration at plate

$\bar{C}_{\infty} \quad$ fluid concentration away from plate

$k_{0} \quad$ permeability coefficient

$B_{0} \quad$ strength of external magnetic field

$C_{p} \quad$ specific heat at constant pressure

D mass diffusion coefficient

$k_{l} \quad$ rate of chemical reaction

$y$ dimensionless horizontal coordinate

$u \quad$ dimensionless axial velocity

$\mathrm{K}$ permeability parameter

Pr Prandtl number

Sc Schmidt number

$M \quad$ Hartmann number

$\mathrm{Gr}$ thermal Grashof number

$\mathrm{Gm}$ solutal Grashof number

E Eckert number

$\gamma \quad$ chemical reaction parameter

\section{Greek symbols}

$v \quad$ kinematic viscosity

$\beta \quad$ coefficient of thermal expansion

$\beta^{*} \quad$ coefficient of concentration expansion

$\sigma \quad$ electrical conductivity

$\rho \quad$ density of the fluid

$\kappa \quad$ thermal conductivity

$\theta \quad$ dimensionless temperature

$\phi \quad$ non-dimensional species concentration 


\section{REFERENCES}

[1] Khair K.R., Bejan A. ,1985, "Mass transfer to natural convection boundary layer flow driven by heat transfer," Int. J. Heat and Mass Transfer, 107, pp.979981.

[2] Khair K.R., Bejan A.,2012, "Mass transfer to natural convection boundary layer flow driven heat transfer," Research Journal of Mathematics and Statistics 4(3), pp.63-69.

[3] Doma S.B., El-Sirafy I.H., El-Sharif A.H.,2010, “Twodimensional fluid past a rectangle plate with variable initial velocity," Alexandria Journal of Mathematics 1, pp. 1-22.

[4] Hossain M.A., Molla M.M. , Yao L.S.,2004, "Natural convection flow along a vertical wavy surface with uniform surface temperature in the presence of heat generation/ absorption," International Journal of Thermal Science 43(2),pp. 157-163.

[5] Kumar H., 2013, "Heat and mass transfer over an isothermal inclined plate at constant concentration gradient and with heat source," World App. Sci. J. 24,pp. 364-369.

[6] Sharma P.R., Singh. G., 2008. "Unsteady MHD free convection flow and heat transfer along a vertical porous plate with variable suction and internal heat generation," International Journal of Applied Mathematics, 4,pp. 1-8.

[7] Ganesan P, Palani G.,2004, "Finite difference analysis of unsteady natural-convection MHD flow past an inclined plate with variable surface heat and mass flux," Int. J. Heat Mass transfer, 47, pp. 4449-4457.

[8] Chen C.H., 2004, "Heat and mass transfer in MHD flow with variable wall temperature and Concentration," Acta Mech. ,172, pp. 219-235.

[9] Hossain M.A., Ahmed M.,1996, "MHD free convection flow from an isothermal plate inclined at a small angle to the horizontal," J. Theo. Appl Fluid Mech ,1,pp. 194-202.

[10] Raptis A., and Konfousius N., 1982, "Magnetohydrodynamic free convective flow and mass transfer through a porous medium bounded by an infinite vertical porous plate with constant heat flux," Canadian Journal of Physics, 60, pp.1725-1729.

[11] Ahmed S.F., Sarkar A.,2009, "MHD natural convection flow of viscous incompressible fluid from a vertical flat plate," J. Phy.Sc., 13, pp. 77-85.

[12] Chand K., Kumar R. , Sharma S.,2012, "Hydromagnetic oscillatory flow through a porous medium bounded by two vertical porous plate with heat source and Soret effect," Advances in Applied Science Research,3(4),pp.2169-2178.

[13] Kandasamy R, Anjali Devi SP.,2004, "Effects of chemical reaction, heat and mass transfer along a wedge with heat source and concentration in presence of suction or injection," J. of Comput. Appl. Mech., 5, pp. 21-31.

[14] Kumar H.,2012, “An analytical solution to the problem of radiative heat and mass transfer over an inclined plate at prescribed heat flux with chemical reaction," J. Serb. Chem. Soc., 77,pp. 1-14.

[15] Anjali Devi, Kandasamy R. ,2000, "Effects of chemical Reaction, Heat and mass transfer on MHD flow past a semi infinite plate," Journal of Applied Mathematics and Mechanics, 80, pp. 697-700.

[16] Chen C.H.,2004, "Combined heat and mass transfer in MHD free convection from a vertical surface with ohmic heating and viscous dissipation," Int. J. Engg. Sci.,42, pp. 699-713.

[17] Kays M.W., Crawford M.E.,1993, Convective heat and mass transfer, Series in Mechanical Engineering, McGraw-Hill, 601.

[18] Patankar S.V. ,1980, Numerical heat transfer and fluid flow, Hemisphere Publishing, New York. 